\title{
ARTICLE
}

Acute lymphoblastic leukemia

\section{Immune cell constitution in bone marrow microenvironment predicts outcome in adult ALL}

\author{
Helena Hohtari, ${ }^{1,2}$ Oscar Brück ${ }^{1,2} \cdot$ Sami Blom $^{3} \cdot$ Riku Turkki $^{3} \cdot$ Marjatta Sinisalo $^{4}$ Panu E. Kovanen ${ }^{5,6}$. \\ Olli Kallioniemi ${ }^{3,7} \cdot$ Teijo Pellinen ${ }^{3} \cdot$ Kimmo Porkka $^{1,2} \cdot$ Satu Mustjoki ${ }^{1,2,8}$
}

Received: 14 July 2018 / Revised: 12 October 2018 / Accepted: 27 November 2018 / Published online: 11 January 2019

(c) The Author(s) 2019. This article is published with open access

\begin{abstract}
As novel immunological treatments are gaining a foothold in the treatment of acute lymphoblastic leukemia (ALL), it is elemental to examine ALL immunobiology in more detail. We used multiplexed immunohistochemistry (mIHC) to study the immune contexture in adult precursor B cell ALL bone marrow (BM). In addition, we developed a multivariate risk prediction model that stratified a poor survival group based on clinical parameters and mIHC data. We analyzed BM biopsy samples of ALL patients $(n=52)$ and healthy controls $(n=14)$ using mIHC with 30 different immunophenotype markers and computerized image analysis. In ALL BM, the proportions of M1-like macrophages, granzyme B + CD57+CD8+ $\mathrm{T}$ cells, and CD27+ T cells were decreased, whereas the proportions of myeloid-derived suppressor cells and M2-like macrophages were increased. Also, the expression of checkpoint molecules PD1 and CTLA4 was elevated. In the multivariate model, age, platelet count, and the proportion of PD1+TIM3+ double-positive CD4+ T cells differentiated a poor survival group. These results were validated by flow cytometry in a separate cohort $(n=31)$. In conclusion, the immune cell contexture in ALL BM differs from healthy controls. CD4+PD1+TIM3 + T cells were independent predictors of poor outcome in our multivariate risk model, suggesting that PD1 might serve as an attractive immuno-oncological target in B-ALL.
\end{abstract}

These authors contributed equally: Helena Hohtari, Oscar Brück

Supplementary information The online version of this article (https:// doi.org/10.1038/s41375-018-0360-1) contains supplementary material, which is available to authorized users.

Satu Mustjoki

satu.mustjoki@helsinki.fi

1 Hematology Research Unit Helsinki, University of Helsinki, Helsinki, Finland

2 Department of Hematology, Helsinki University Hospital Comprehensive Cancer Center, Helsinki, Finland

3 Institute for Molecular Medicine Finland, University of Helsinki, Helsinki, Finland

4 Department of Internal Medicine, Tampere University Hospital, Tampere, Finland

5 Department of Pathology, University of Helsinki, Helsinki, Finland

6 HUSLAB, Helsinki University Hospital, Helsinki, Finland

7 Department of Oncology and Pathology, Science for Life Laboratory, Karolinska Institutet, Solna, Sweden

8 Department of Clinical Chemistry, University of Helsinki, Helsinki, Finland

\section{Introduction}

Acute lymphoblastic leukemia (ALL) is a malignant disease of the early lymphoid precursors, which occurs in all age groups. The contemporary survival rates in children are excellent, whereas the treatment results in adults are still suboptimal and most patients die of their leukemia. Current treatment consists of multiagent chemotherapy to induce and consolidate remission, followed by prolonged maintenance therapy [1, 2]. Treatment guided by sensitive monitoring of minimal residual disease (MRD) and the introduction of pediatric-modeled regimens in younger adults have improved patient outcome [3-5].

Philadelphia chromosome-positive $(\mathrm{Ph}+)$ ALL forms the largest subgroup in adult ALL [6]. Introducing tyrosine kinase inhibitors (TKIs) into treatment regimens has improved survival in $\mathrm{Ph}^{+}$ALL [7-9]. In addition to direct oncokinase inhibition, TKI therapy modulates the immune system, which may play a critical role in suppressing the growth of leukemic cells [10-14].

In addition to the anti-CD20 antibody rituximab, novel immunotherapeutic approaches such as anti-CD3-CD19 
bispecific blinatumomab, chemotherapy-conjugated antiCD22 antibody inotuzumab ozogamicin, and CD19-specific chimeric antigen receptor (CAR) T cell therapy have shown promising results [15-18]. Despite recent advances in the treatment, considerable number of ALL patients still experience relapse and leukemia-related death.

In solid tumors, the immune contexture has been shown to impact outcome [19]. In ALL, the immunological status of the bone marrow (BM) niche has not been thoroughly studied, even though increasing evidence suggests that the immune system contributes both to the development and outcome of leukemia [20,21]. Given the success of novel immunotherapies in oncology, unveiling the immunological basis of ALL is warranted.

In this study, we present a detailed description of immune cell constitution in adult precursor B cell ALL BM microenvironment at diagnosis using multiplex immunohistochemistry (mIHC) and computerized image analysis (Fig. 1a). The quantitated immune cell subsets were correlated with clinical parameters, stratifying a poor outcome group with increased number of CD4+PD1+TIM3+ $\mathrm{T}$ cells, higher age, and a low peripheral blood $(\mathrm{PB})$ platelet count at diagnosis. These findings were validated in a separate cohort using multicolor flow cytometry (FC). Together, these results shed light on the immunological composition prevailing in ALL BM and its clinical significance.

\section{Materials and methods}

\section{Study design}

\section{Discovery cohort}

To study immune cell constitution in ALL using mIHC, we collected deposited, diagnostic-phase, formalin-fixed, and paraffin-embedded (FFPE) BM biopsies of adult precursor B cell ALL patients $(n=52)$. The cohort was retrospective and included both $\mathrm{Ph}^{+}(n=31)$ and $\mathrm{Ph}^{-}(n=21)$ patients. Five patients were treated in Tampere University Hospital (Finland) and the others in Helsinki University Hospital (HUH; Finland). Patients with a previously treated malignancy were excluded. BM biopsies from healthy controls ( $n$ $=14$ ) were used as a reference. Control patients were referred to the hematology or internal medicine outpatient clinic most commonly due to unclear thrombocytosis or anemia, but neither hematologic malignancy, chronic infection, nor autoimmune disease was found in diagnostic examinations and 6-year follow-up (Supplementary Table S1). The patients signed a written informed consent for the study and for collection of clinical data to the Finnish Hematology Registry (FHR). The study was conducted in accordance with the Declaration of Helsinki and the HUH Ethical Committee (DNRO 303/13/03/01/2011).

\section{Validation cohort}

To validate the prognostic biomarkers that were found in mIHC, we used FC to analyze BM samples from 31 precursor B cell ALL patients treated in all university hospitals across Finland. The cohort was retrospective and included both $\mathrm{Ph}^{+}(n=13)$ and $\mathrm{Ph}^{-}(n=18)$ patients. The samples were viably frozen diagnostic-phase BM mononuclear cells obtained from the Finnish Hematology Registry and Clinical Biobank (FHRB, fhrb.fi).

\section{Clinical data}

As seven patients had samples in both cohorts, we studied in total 76 ALL patients. FHR served as a source for attaining patient-related clinical data. In both cohorts, we assessed altogether 33 clinical variables, including baseline laboratory values, MRD status at different time points, CD20-positivity, spleen size, comorbidities, performance score, and status of allogeneic hematopoietic stem cell transplantation (alloHSCT) (Supplementary Table S2). The observation time started from the day of diagnosis and ended when an event (relapse or death due to any cause) occurred or, in the absence of an event, at the last day of follow-up.

In the Discovery cohort, six $\mathrm{Ph}^{+}$ALL patients were treated prior to the TKI era and were excluded from the survival analysis. One $\mathrm{Ph}^{-}$ALL patient had received nonprotocol treatment and another was treated with an older protocol and were therefore excluded from the survival analysis. All patients $(n=44)$ in the survival analysis were treated according to Finnish Leukemia Group (FLG) ALL2000 protocol or NOPHO ALL-2008 protocol [3]. In addition, all $\mathrm{Ph}^{+}$patients $(n=25)$ received TKIs as part of their treatment protocol. The patients in the Validation cohort received treatments according to the same protocols as the Discovery cohort.

\section{Patient characteristics}

A detailed list of patient characteristics is found in Table 1 . The patients in different cohorts did not differ significantly in terms of age, diagnostic-phase laboratory values, performance score, or alloHSCT prevalence (Mann-Whitney $U$ test for continuous and Fisher's exact test for categorical variables). There were slightly more females in the Discovery cohort than in the Validation cohort $(45 \%$ vs. $35 \%)$. Healthy controls did not differ significantly from the Discovery cohort in terms of age or gender distribution. 


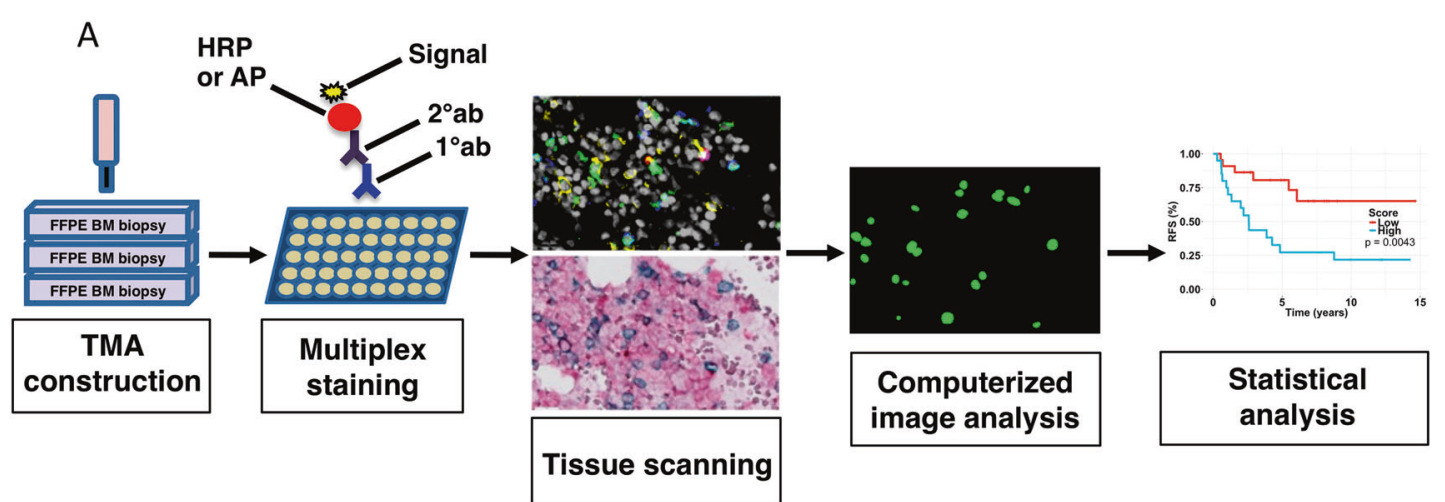

B

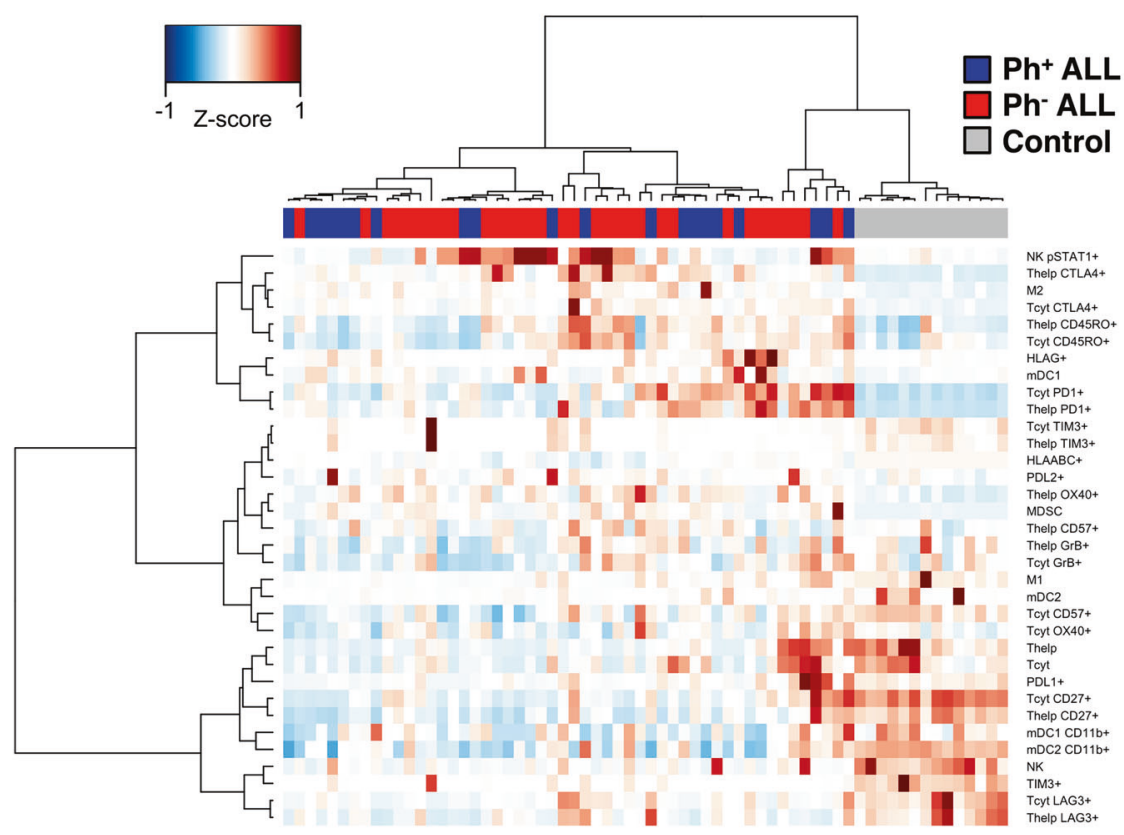

C

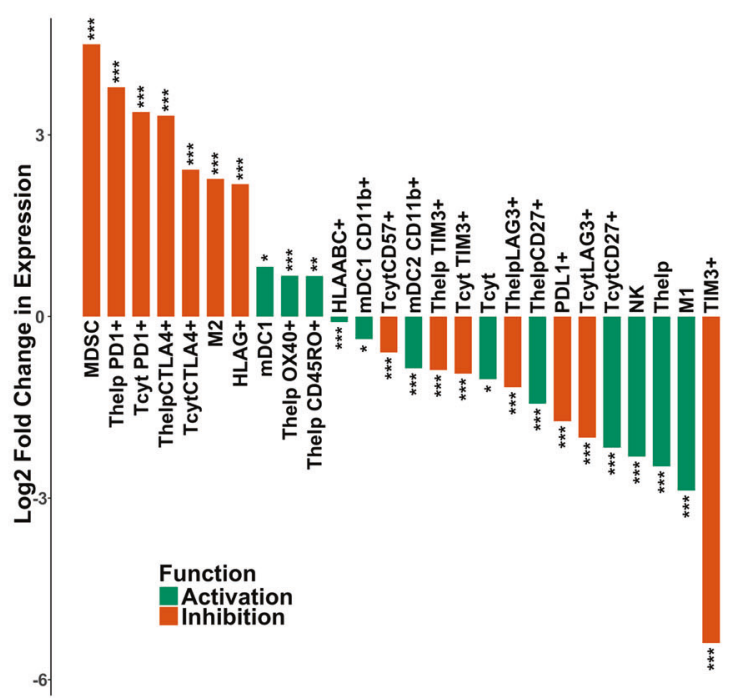


Fig. 1 a Overview of the tissue microarray (TMA) analysis pipeline. TMAs were constructed from duplicate bone marrow (BM) biopsy punches from regions with high leukemic cell infiltration. TMA slides were then stained with multiplexed immunohistochemistry (mIHC) consisting of 5-plex fluorescent and 3-plex chromogenic dyes. Histological images were scanned and registered, and then cells were segmented based on differential spatial intensity using Otsu's thresholding method. The intensity of each marker was quantified and classified. Finally, expression profiles of various markers were aggregated for more detailed data analysis. FFPE formalin-fixed paraffin-embedded. b Heatmap visualization of quantified immune cells (proportion of all cells) and their immunophenotypes (proportion of the parent immune cell). Spearman correlation distance and Ward linkage (ward.D2) method were used for hierarchical clustering. c ALL-to-control ratios were transformed by two-fold logarithmic transformation and annotated according to literature as anticancer immunity (green) or immunosuppression marker (orange). Only significantly varying $(q<$ 0.05; Benjamini-Hochberg-adjusted Mann-Whitney $U$ test) median values are included. It should be noted that, in case of particularly low cell numbers, this representation may skew the output, and the color annotations are a simplification of a much more diverse reality. For example, the absolute count of TIM3-expressing T cells was low both in ALL patients and controls (Fig. 2c), but the proportional difference was almost six-fold

\section{Methods}

\section{Tissue microarrays (TMAs)}

An experienced hematopathologist evaluated the FFPE BM biopsies marking out the most representative areas with high leukemic cell infiltration. Duplicate $1 \mathrm{~mm}$ diameter spots were taken from the selected areas for TMA construction. Control spots from non-ALL patients were chosen from tissue regions with high cellularity.

\section{Multiplexed immunohistochemistry}

The TMA sections were stained with both 5-plex fluorescent and subsequent 3-plex chromogenic staining. Immune cell panels included antibodies to detect $\mathrm{B}$ and $\mathrm{T}$ lymphoid cells, natural killer (NK) and dendritic cells (DCs), macrophages, and myeloid-derived suppressor cells (MDSCs) (Supplementary Table S3). In addition, clinically relevant immune checkpoint receptors (PD1, LAG3, OX40, TIM3, CTLA4, HLA-ABC) and ligands (PD-L1, PD-L2, HLA-G) alongside with various activation markers were analyzed. The original protocol is described in detail by Blom et al. and adapted by Brück et al. [22, 23]. For antibodies, see supplementary Table S4.

\section{Image preprocessing}

The individual chromogen staining signals were separated by deconvolving the brightfield images [24]. Spot images were then registered with two-dimensional phase correlation method using mean image of both fluorescent and
Table 1 Patient characteristics of the Discovery (mIHC) and Validation (FC) cohort subjects included in survival analyses

\begin{tabular}{lll}
\hline Variable & $\mathrm{mIHC}(n=44)$ & $\mathrm{FC}(n=31)$ \\
\hline Gender, female (\%) & 45 & 35 \\
Gender, male (\%) & 55 & 65 \\
AlloHSCT (\%) & 55 & 52 \\
Diagnostic data (median, range) & \\
Age (years) & $47(16-72)$ & $43(19-69)$ \\
$\mathrm{Ph}^{+}(\%)$ & 57 & 42 \\
CD20+ (\%) & 36 & 58 \\
Leukocytes (10E9/1) & $15.6(0.4-174)$ & $18.4(0.9-188.5)$ \\
Platelets (10E9/1) & $47(3-233)$ & $45(3-252)$ \\
BM blasts (\%) & $90(50-100)$ & $90(50-100)$ \\
WHO $^{\mathrm{a}} \geq 1(\%)$ & 66 & 71 \\
\hline
\end{tabular}

There were no significant differences between the cohorts (MannWhitney $U$ test for continuous and Fisher's exact test for categorical variables). The lowest pretreatment platelet count \pm 2 days around the diagnosis date was selected

alloHSCT allogeneic hematopoietic stem cell transplantation, $B M$ bone marrow, $m I H C$ multiplexed immunohistochemistry, $F C$ flow cytometry

${ }^{\mathrm{a}} \mathrm{WHO} / \mathrm{ECOG}$ performance scale

brightfield channels [25]. Before registration, mean images were downsized by a factor of eight and image histograms were adapted to each other. Image preprocessing was performed in a numerical computing platform (MATLAB, MathWorks, Natick, MA, US).

\section{Image analysis}

Gray-scale image channels of each TMA spot were evaluated in order to ensure the staining quality. Blurred focusing or unsuccessful image registration led to image disqualification. Unsuccessful registration was mostly induced by air bubbles in mounting media or shattered tissue. We segmented cell masks with parent immune cell markers (e.g., CD3 for $\mathrm{T}$ cells) using Otsu's thresholding method and separated single cells from aggregates using intracellular intensity patterns. Cell segmentation, intensity measurements, and cell classification were implemented in an image analysis platform (CellProfiler 2.1.2 [26-28]). Total cell number for each TMA spot was calculated with Fiji from the total area of binary 4,6diamidino-2-phenylindole images. Single-cell analysis (FlowJo v10; SI) was used for marker co-localization and cell classification with integrated intensity.

TMA spots with $<1000$ cells were excluded. In order to avoid bias due to cell number variation between spots, each immune cell type was quantified either as a proportion of all cells in each TMA spot or as a proportion of a defined immunophenotype to the particular cell type (e.g., CD3 $+\mathrm{CD} 4+/ \mathrm{PD} 1+\mathrm{TIM} 3+\mathrm{T}$ cells of all $\mathrm{CD} 3+\mathrm{CD} 4+\mathrm{T}$ cells [\%]). The mean values of each cell class or 
immunophenotype were calculated from the duplicate spots obtained from the same BM sample.

\section{Flow cytometry}

Viably frozen $\mathrm{BM}$ mononuclear cells $(N=31)$ were first thawed and stained using CD3-PerCP-Cy5.5 (SK7, BD Pharmingen), CD8-FITC (SK1, BD Pharmingen), CD4BV510 (SK3, BD Pharmingen), TIM3-PE-Cy7 (F38-2E2, Invitrogen), PD1-AlexaF647 (EH12.1, BD Pharmingen), CD45-BV421 (HI30, BD Horizon), CCR7-PE (150503, R\&D Systems), and CD45RA-AlexaF700 (HI100, BD Pharmingen) antibodies. Fluorescence was measured with FACSVerse (BD Pharmingen). The proportion of CD3+CD4 + /PD1+TIM3 + cells was used in survival analysis similarly as with mIHC data (Supplementary Figure S1).

\section{Statistical analysis}

The mIHC stainings were executed in two separate batches. In order to eliminate a batch effect, data were meancentered. Mann-Whitney $U$ test was used for comparing two groups of continuous variables. For multiple test correction, Benjamini-Hochberg's method was applied [29]. To examine associations between survival, clinical parameters, and mIHC results, all variables with $P<0.20$ (logrank test, supplementary Table S5) in univariate Cox proportional hazards analysis were included in a L1-penalized elastic net regression analysis that performs both model shrinkage and variable selection [30]. The shrinkage parameter lambda $(\lambda)$ was defined by minimum mean crossvalidated error. Scaled Schoenfeld residuals were used to confirm the proportional hazards assumption of the model. In addition, competing risks were analyzed with Gray's test [31]. We assessed model prediction by comparing the area under the receiver operating characteristic (AUROC) curves (bootstrap method, number of iterations: 4000), timedependent ROC curves (IPCW [inverse probability of censoring weighting] approach), and $C$-statistic values of different models. Statistical analyses were performed with $\mathrm{R}$ v3.3.3 [32] and Prism v7.0 (GraphPad Software Inc). R packages glmnet, corrplot, survminer, survival, ggplot2, cmprsk, pROC, plotROC, timeROC, and gplots were used for statistical analysis and data visualization.

\section{Results}

\section{Immune cell composition in ALL BM microenvironment differs from healthy}

In order to visualize immune profiles of ALL patients $(n=$ $52)$ and controls $(n=14)$ analyzed with mIHC (Discovery cohort), we mapped quantified immune cells and their single-marker phenotypes (Fig. 1b). Hierarchical clustering analysis revealed that immune cell subtypes linked with cytolytic activity (e.g. NK cells and granzyme B-positive $\mathrm{T}$ cells) were decreased and immunoregulatory markers (e.g., CTLA4+ T cells and MDSCs) increased in ALL BM, grouping ALL patients and controls distinctly from each other. The immune contexture of $\mathrm{Ph}^{+}$ALL BM did not differ from $\mathrm{Ph}^{-}$ALL BM.

Next we assessed significant (Mann-Whitney $U$ test, $q<$ $0.05)$ differences between immune cell subsets and their phenotypes in ALL vs. control BM. Immune cell subtypes and markers associated with regulation of immune responses (e.g., MDSCs, PD1, and CTLA4) were elevated in ALL $\mathrm{BM}$, whereas pro-inflammation-related markers (e.g., M1 macrophages, $\mathrm{NK}$ cells, and $\mathrm{CD} 27+\mathrm{T}$ cells) were decreased (Fig. 1c).

\section{ALL BM is reflected by diminished proportion of activated T cells and M1 macrophages, as well as lowered cytolytic activity}

A $\mathrm{T}$ helper type 1 (Th1)-driven immune response and especially CD8 $+\mathrm{T}$ cells have been associated with beneficial prognosis and anticancer protection [33]. In addition, M1-like macrophages secrete high levels of inflammatory cytokines and are associated with antitumor responses [34]. Therefore, we investigated whether the levels of CD8+ $\mathrm{T}$ cells, NK cells, and M1-polarized macrophages are affected in ALL patients. The proportion of M1-like macrophages was decreased $(0.8 \%$ vs. $5.9 \%$ of CD68+ cells in ALL compared to healthy BM, $q=0.0002$; Fig. 2a). Similarly, the proportion of CD8+granzyme B+CD57+ $\mathrm{T}$ cells $(11.5 \%$ vs. $24.0 \%$ of CD8+ T cells, $q=0.0001)$ as well as CD27 $+\mathrm{T}$ cells $(7.9 \%$ vs. $21.5 \%$ of $\mathrm{CD} 3+\mathrm{CD} 4+$ $\mathrm{T}$ cells, $q<0.0001$ and $7.7 \%$ vs. $34.6 \%$ of $\mathrm{CD} 3+\mathrm{CD} 8+$ $\mathrm{T}$ cells, $q<0.0001$; Supplementary Figure S2) was decreased in ALL BM, suggesting suppressed cytolytic and co-stimulation ability, respectively. The proportion of NK cells of all cells $(0.2 \%$ vs. $0.9 \%, q<0.0001$, Fig. 2 b) was decreased in comparison to controls.

\section{Increased levels of myeloid M2-polarized macrophages and MDSCs in ALL BM}

As M2-like macrophages and MDSCs are able to promote tumor growth by dampening Th1-mediated immune responses, we next examined the level of immunosuppressive myeloid cells [34, 35]. M2-like macrophages were enriched in ALL BM (8.3 vs. 1.7\%, of CD68+ cells, $q<$ 0.0001 ; Fig. 2a). Similarly, the proportion of MDSCs was increased $(0.9 \%$ vs. $0.04 \%$ of all cells, $q<0.0001$; Fig. 2b). 

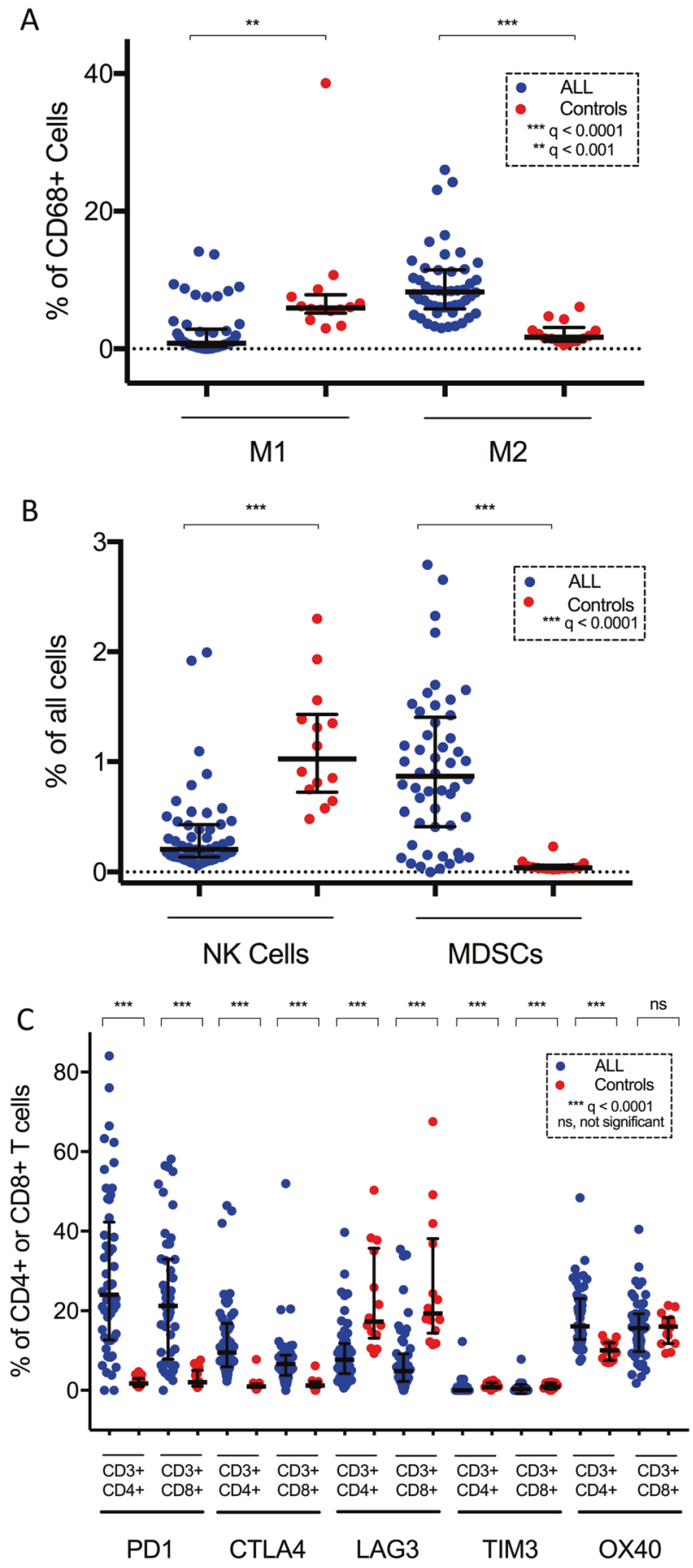

Fig. 2 Levels of a M1-like and M2-like macrophages; b Natural killer (NK) cells and myeloid-derived suppressor cells (MDSCs); c PD1-, TIM3-, CTLA4-, LAG3-, and OX40-expressing T cells in multiplexed immunohistochemical analysis were compared with Mann-Whitney $U$ test and $p$ values adjusted using Benjamini-Hochberg method ( $q$ values). $* * \mathrm{q}<0.001, * * * \mathrm{q}<0.0001$

\section{The expression of immune checkpoints PD1 and CTLA4 is upregulated in T cells}

Next, we evaluated the expression of pivotal immune checkpoint molecules in T cells (Fig. 2c). The expression of
PD1 (24.0 vs. $1.7 \%$ of CD4+ cells, $q<0.0001$ and 21.2 vs. $2.0 \%$ of CD8 cells, $q<0.0001$ ) and CTLA4 (9.4 vs. $0.9 \%$ of CD4 + cells, $q<0.0001$ and 6.6 vs. $1.2 \%$ of CD $8+$ cells, $q$ $<0.0001)$ was pronounced in ALL BM. However, the expression of LAG3 (7.7 vs. $17.3 \%$ of CD4+ cells, $q<$ 0.0001 and 4.8 vs. $19.3 \%$ of CD $8+$ cells, $q<0.0001)$ and TIM3 ( 0.0 vs. $0.8 \%$ of CD4+ cells, $q<0.0001$ and 0.0 vs. $0.9 \%$ of CD8 + cells, $q<0.0001)$ were decreased in ALL compared to the control BM. The expression of OX40 was increased in CD4+ $\mathrm{T}$ cells $(16.1$ vs. $10.1 \%$ of $\mathrm{CD} 4+$ cells, $q<0.0001$ ), but no difference was seen in CD8+ T cells.

\section{Antigen-presenting myeloid DC type 1 (mDC1) and CD4-positive memory $\mathrm{T}$ cells are increased in ALL BM}

$\mathrm{T}$ cell priming is dependent on antigen presentation. $\mathrm{mDC} 1$ are essential in presenting cancer-related antigens and inducing a Th1-fashioned immune response by producing high amounts of interleukin-12 [36]. The proportion of $\mathrm{mDC} 1 \mathrm{~s}$ was enriched (3.5\% [interquartile range (IQR) 1.7$5.3 \%$ ] vs. $2.0 \%$ [IQR $1.1-2.8 \%$ ] of all cells, $q=0.03$ ). In addition, the proportion of $\mathrm{CD} 4+\mathrm{CD} 45 \mathrm{RO}+$ memory $\mathrm{T}$ cells $(41.0 \%$ [IQR $30.5-51.4 \%$ ] vs. $25.8 \%$ [IQR 19.1$30.1 \%$ ] of CD4+ cells, $q=0.002$ ) was elevated. The percentage of $\mathrm{CD} 8+\mathrm{CD} 45 \mathrm{RO}+\mathrm{T}$ cells was increased as well but did not reach statistical significance.

\section{CD4+PD1+TIM3 + T cells, platelet count, and age predict survival}

To study the synergy and translational significance of immune profiles and clinical parameters, we performed L1penalized Cox regression analysis on preselected covariates $(P<0.20$ in univariate Cox regression). The resulting risk model was used to stratify patients into dichotomous, equally sized groups (i.e., high-risk and low-risk groups). The primary endpoint was relapse-free survival (RFS).

In the risk stratification model, high expression of BM CD4+PD1+TIM3+ T cells, age above the cohort median, and low PB platelet count at diagnosis differentiated a poor survival group. Furthermore, multiple other potential immune biomarkers were discovered in univariate analysis, even though these did not stand out in our multivariate model (Supplementary Table S5). The hazard ratio (HR) for overall survival (OS) in the high-risk group was 4.9 (95\% confidence interval (CI) 1.8-13.3; $P=0.0007$, log-rank test; Fig. 3a), for RFS 3.7 (95\% CI 1.4-9.6; $P=0.004$, logrank-test; Fig. 3b), and for event-free survival (EFS) 4.0 (95\% CI 1.6-10.3; $P=0.002$; Supplementary Figure S3A, B). The competing risk analysis demonstrated that both deaths $(P=0.052$, Gray's test $)$ and relapses $(P=0.072)$ were more prevalent and censoring less prevalent 
A

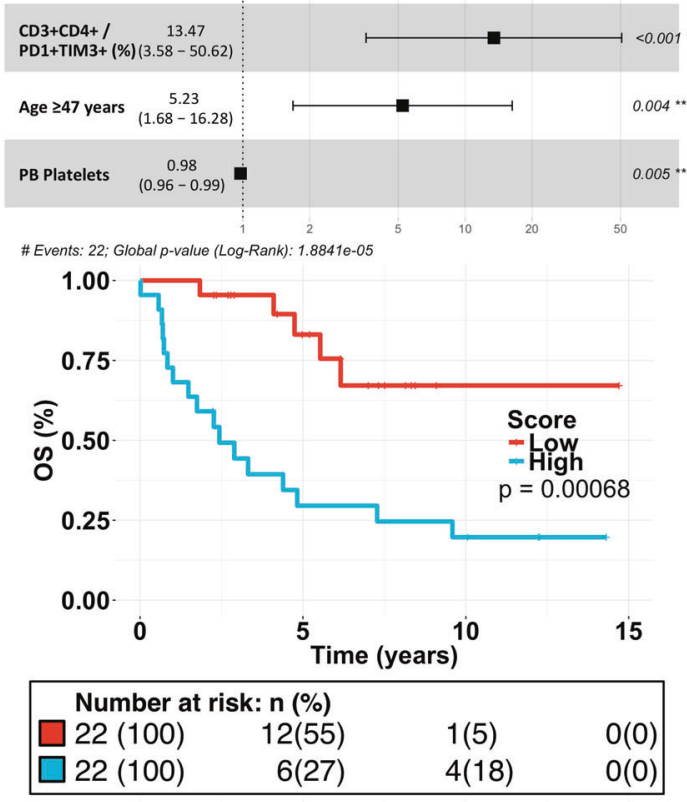

C

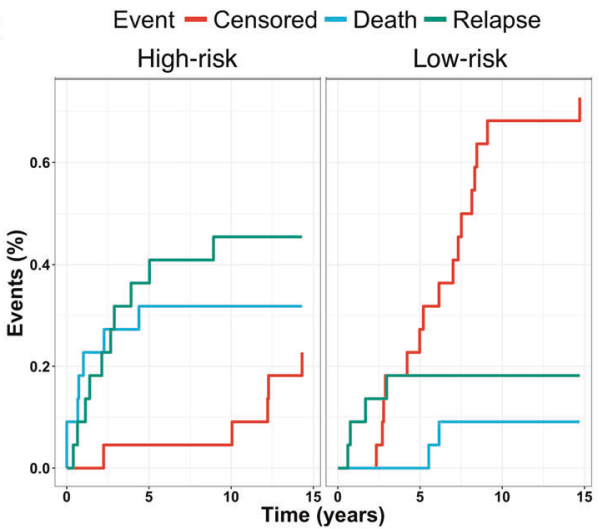

E

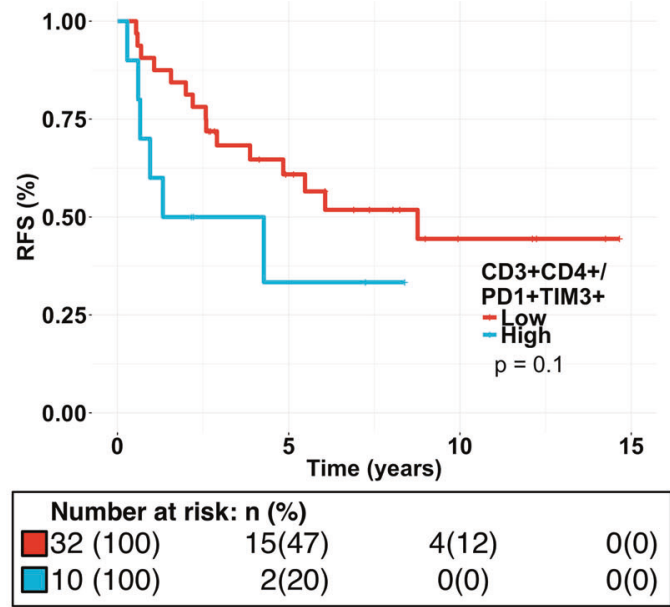

B

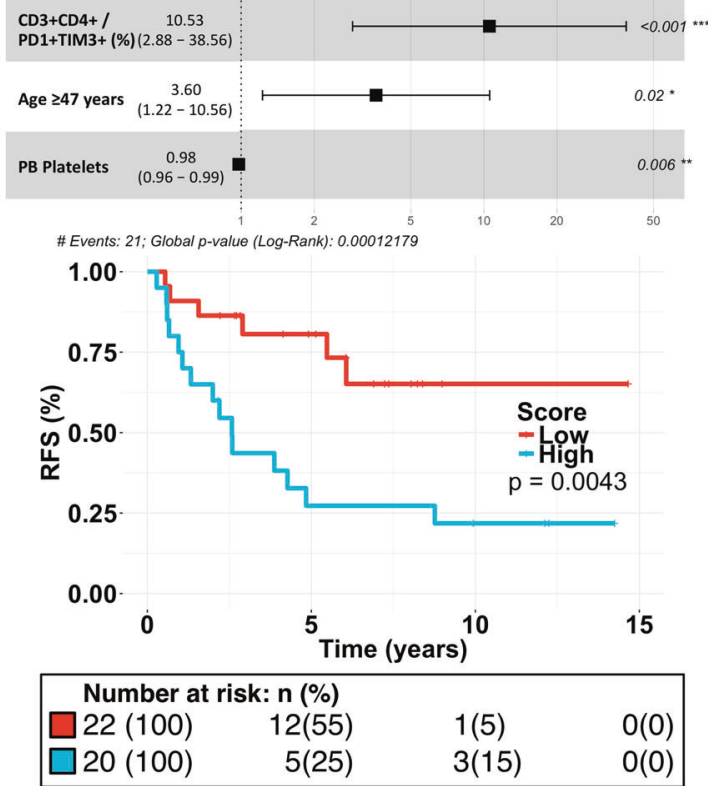

D 1.00 .

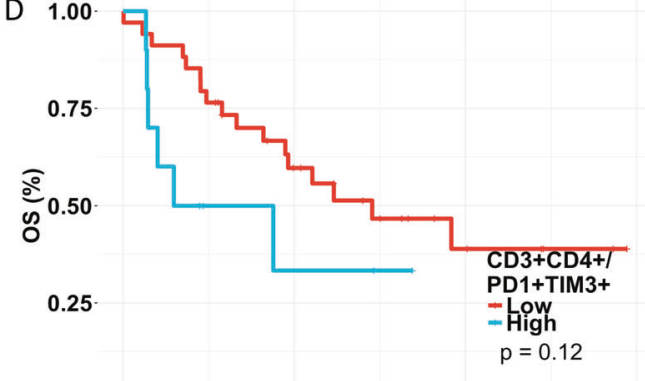

0.00

\begin{tabular}{|c|c|c|c|}
\hline 0 & \multicolumn{2}{|c|}{5 Time (years) ${ }^{10}$} & 5 \\
\hline \multicolumn{2}{|c|}{ Number at risk: $\mathbf{n}(\%)$} & & \\
\hline$\square 34$ (100) & $16(47)$ & $5(15)$ & $0(0)$ \\
\hline$\square 10$ (100) & $2(20)$ & $0(0)$ & $0(0)$ \\
\hline
\end{tabular}

F

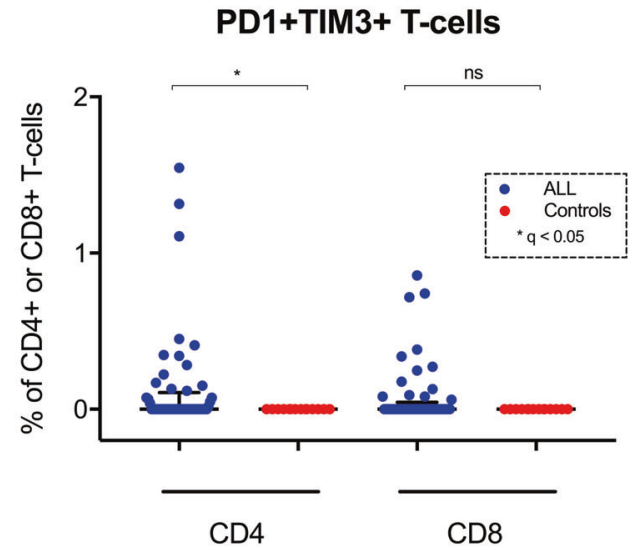

survival (Fig. 3d, e; Supplementary Figure S3C), and relapses were more common in high-expressing patients in competing risk analysis (Supplementary Figure S3D). 
Fig. 3 Survival analysis in the Discovery cohort (multiplex immunohistochemistry). Forest plot of the risk stratification model for a OS (overall survival) and b RFS (relapse-free survival). The risk stratification model was divided by median into high- and low-risk groups and plotted for a OS and b RFS (Cox regression analysis, log-rank test). c Competing risk analysis of EFS was performed for the highand low-risk group stratification model (Gray's test). d OS and e RFS curves (Cox regression analysis, log-rank test) for patients categorized by PD1+TIM3 + high-expressing (cutoff $>0.1 \%$ CD4+PD1+TIM3+ $\mathrm{T}$ cells) and low-expressing groups. $\mathbf{f}$ Levels of PD1+TIM3+ doublepositive $\mathrm{T}$ cells in ALL and healthy control bone marrow. $* \mathrm{q}<0.05$

Although the mean proportion of PD1+TIM3 $+\mathrm{T}$ cells in ALL patients is low, it is heterogeneously expressed (mean $0.12 \%$, range $0-1.55 \%$, standard deviation (SD) 0.31 ; Fig. 3f). Patient characteristics of the high- and low-risk groups in the risk stratification model are described in Supplementary Table S6. The high-risk group was characterized with higher BM blast proportion $(P=0.003)$, but no other association with clinical parameters was found.

The results were validated in the Validation cohort. Even with a sample size of 31 patients, high proportion of CD4 +PD1+TIM3 + T cells (divided according to cohort median), higher age (divided according to cohort median), and low platelet count predicted poor OS (HR 4.7, 95\% CI 0.98-22.5; $P=0.03$, log-rank test; Fig. 4a), RFS (HR 4.9, 95\% CI 1.3-19.0; $P=0.01$, log-rank test; Fig. 4b), and EFS (HR 4.4, 95\% CI 1.3-14.2; $P=0.009$; Supplementary Figure S4A, B). The mean proportion of PD1+TIM3+ $\mathrm{T}$ cells remained small in ALL samples (mean $0.88 \%$, range $0.00-10.11 \%$, SD 1.88). Similarly, in univariate analysis, high proportion of CD4+PD1+TIM3 $+\mathrm{T}$ cells trended toward poor RFS and EFS but not OS (Fig. 4c, d; Supplementary Figure S4C). In competing risk analysis, relapses were more prevalent in high-risk patients $(P=$ 0.014, Gray's test; Fig. 4e) and censoring less common $(P=0.013)$ in patients with PD1+TIM3+ expression superior to median in CD4+ $\mathrm{T}$ cells (Supplementary Figure S4D). Patient characteristics of the risk groups in the Validation cohort are described in Supplementary Table S6.

\section{High proportion of PD1+TIM3 + T cells is associated with immunologic activity}

As the proportion of CD4 $+\mathrm{T}$ cells expressing PD1+TIM3+ were associated with poor survival, we next studied the interaction of CD4+PD1+TIM3 $+\mathrm{T}$ cells with clinical and immune parameters. There was no correlation between PD1 +TIM3 + expression and clinical laboratory parameters or age (Supplementary Figure S5). Interestingly, the abundance of $\mathrm{CD} 4+$ and $\mathrm{CD} 8+\mathrm{T}$ cells and their expression of GrB and TIM3 and the number of MDSCs correlated (Spearman correlation) positively with CD4+PD1+TIM3+ $\mathrm{T}$ cells (Fig. 5a).
Integrating MRD status to the multivariate model

Achieving MRD negativity is one of the strongest predictors of outcome in adult ALL [37]. Therefore, we compared long-term survival prediction ability of our multivariate risk model to risk stratification by MRD status at 4 months post-diagnosis. MRD was primarily measured using polymerase chain reaction (PCR)-based approaches (quantitative reverse transcription PCR/allelespecific oligonucleotide-PCR), but in the absence of a suitable follow-up marker for PCR, MRD measurement using multiparameter FC with sufficient sensitivity $\left(10^{-4}\right)$ was accepted as well. MRD negativity was defined as $<10^{-4}$ leukemic blasts per healthy cells. Our model predicted RFS, EFS, and OS with higher confidence than MRD monitoring or risk stratification according to original NOPHO-ALL2008 [3] or FLG ALL2000 protocols (Supplementary Table S7) using AUROC comparison (bootstrap method; Fig. 5b and Supplementary Figure S6A, B) and trended toward superior prediction with both $C$-statistic and time-dependent AUC comparison (IPCW approach; Fig. 5c and Supplementary Figures S6C, D). Interestingly, by supplementing MRD status at 4 months with the immunoprofiling model, each covariate remained independent $(P<0.05)$ and the overall model improved prediction. Similar model improvement did not occur if the model was combined with NOPHOALL and ALL2000 risk classification.

\section{Discussion}

The results of integrative immune profiling suggest that immune cell subtypes and markers associated with immune regulation (such as MDSCs, PD1, and CTLA4) are increased in ALL BM compared to healthy controls. In addition, high proportion of CD4+PD1+TIM3+ doublepositive $\mathrm{T}$ cells, older age, and low platelet count at diagnosis identified a group with poor survival in two separate cohorts.

mIHC allows in-depth cytometric evaluation of different immune cell subtypes in their original BM microenvironment. When analyzing samples in the TMA format, hundreds of samples and tens of different marker combinations can be analyzed simultaneously [38]. FFPE preserves samples and bypasses the possible effects of cryopreservation on cell number, viability, and phenotype [39], thus serving retrospective discovery studies ideally. Our mIHC approach was supplemented with automated image analysis for fast and objective immune cell classification and quantification. We validated prognostic biomarkers with FC, which is used in routine clinical practice for diagnostic and follow-up purposes. 
A

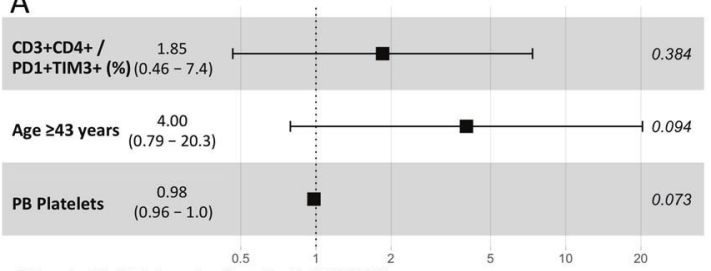

\# Events: 11; Global p-value (Log-Rank): 0.0069483

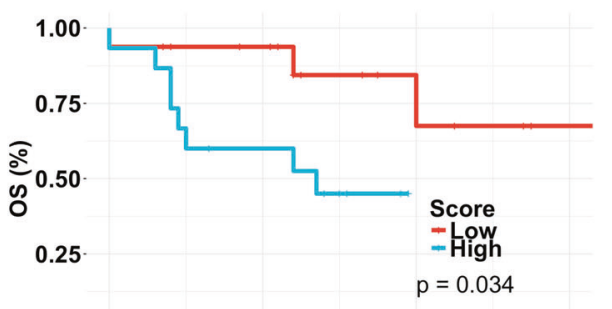

0.00

\begin{tabular}{|c|c|c|c|}
\hline \multicolumn{4}{|c|}{$20 \quad 40$} \\
\hline \multicolumn{4}{|c|}{ Number at risk: $\mathrm{n}(\%)$} \\
\hline$\square 16(100)$ & $12(75)$ & $5(31)$ & $1(6)$ \\
\hline$\square 15$ (100) & $8(53)$ & $0(0)^{\prime}$ & $0(0)$ \\
\hline
\end{tabular}

C

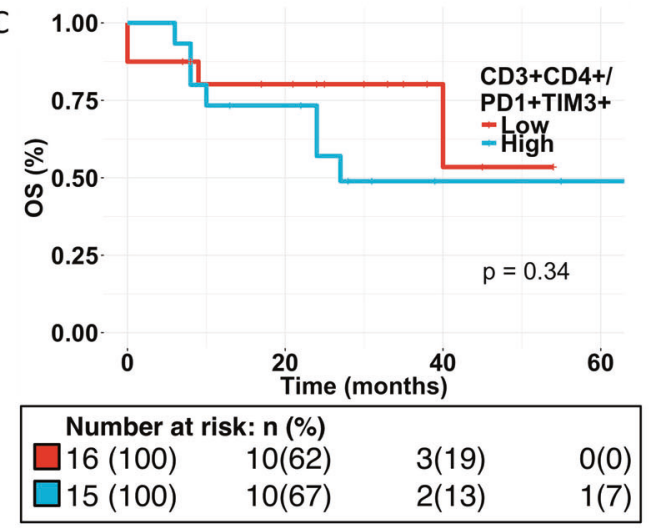

Event - Censored $=$ Death - Relapse

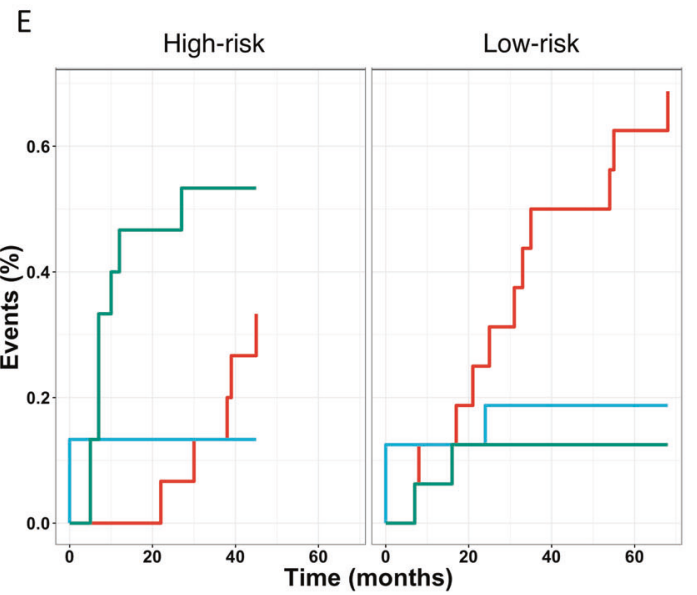

Fig. 4 Survival analysis in the Validation cohort (flow cytometry). Forest plot of the risk stratification model for a OS (overall survival) and b RFS (relapse-free survival). The risk stratification model was divided by median into high- and low-risk groups and plotted for a OS and $\mathbf{b}$ RFS (Cox regression analysis, log-rank test). Survival curves of

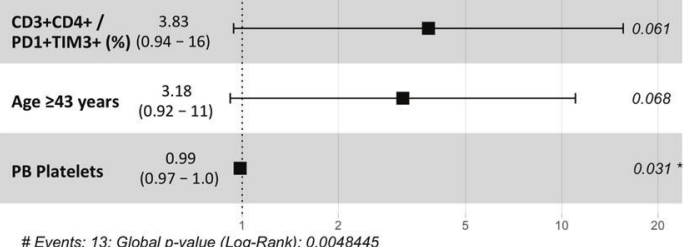

\# Events: 13; Global p-value (Log-Rank): 0.0048445

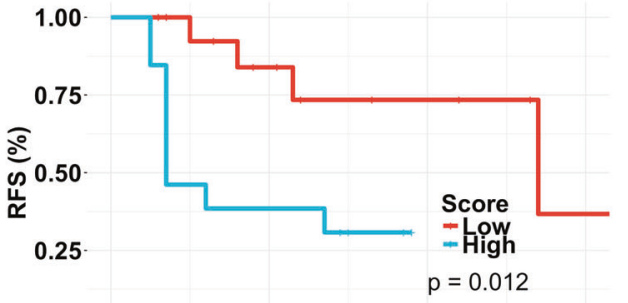

0.00

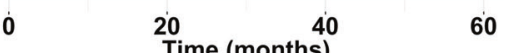

\begin{tabular}{|lccc|}
\hline \multicolumn{2}{|c|}{ Number at risk: $\mathbf{n}(\%)$} \\
$\square 15(100)$ & $9(60)$ & $4(27)$ & $1(7)$ \\
$\square 13(100)$ & $5(38)$ & $0(0)$ & $0(0)$ \\
\hline
\end{tabular}

D

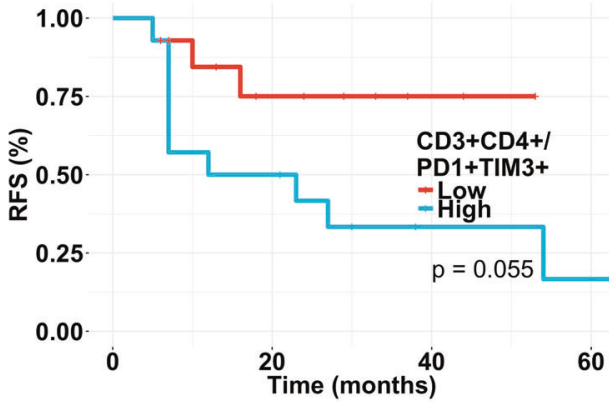

\begin{tabular}{|cccc|}
\hline \multicolumn{2}{|c|}{ Number at risk: $\mathbf{n}(\%)$} \\
$\square 14(100)$ & $7(50)$ & $2(14)$ & $0(0)$ \\
$\square 14(100)$ & $7(50)$ & $2(14)$ & $1(7)$ \\
\hline
\end{tabular}

$\mathrm{CD} 3+\mathrm{CD} 4+/ \mathrm{PD} 1+\mathrm{TIM} 3+$ cells categorized into two groups by median and plotted for $\mathbf{c}$ OS and d RFS. e Competing risk analysis of EFS was performed for the high- and low-risk group stratification model (Gray's test) 

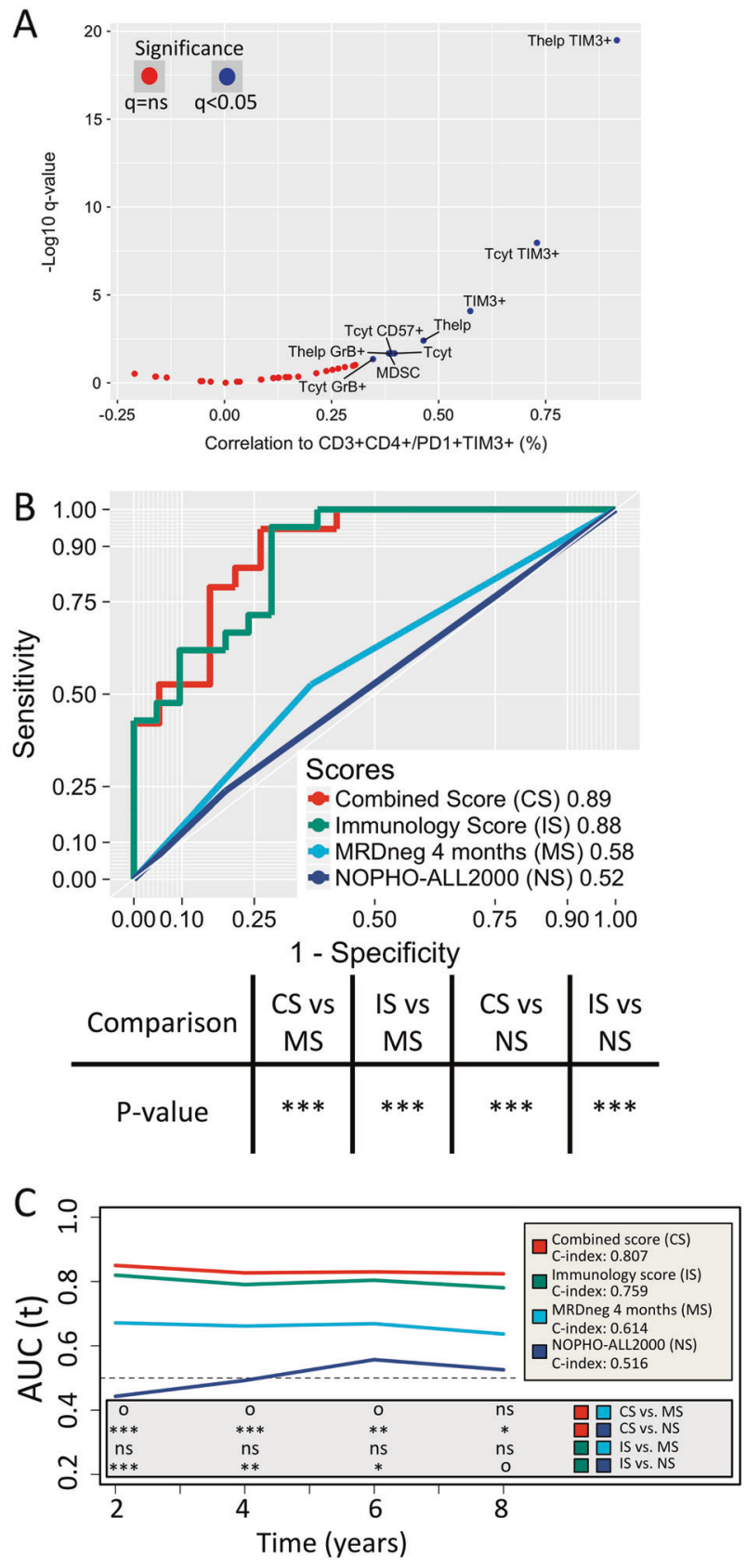

In solid tumors, the immune contexture both before and during treatment has been shown to predict treatment responses to chemotherapy and immune checkpoint therapy as well as survival [40-46]. In hematological malignancies, the role of immune cell composition is still largely unrevealed, and to our knowledge, this is the first comprehensive immunological study on precursor B-ALL BM.

As the immune system of cancer patients is constituted of diverse cell populations engaging in a complex and dynamic interaction [47], we investigated a wide variety of cell populations and phenotype markers with known clinical significance or well-established role in immunology [19, 48, 49].
4 Eig. 5 a The correlation between CD4+PD1+TIM3 + T cell count and other immune cell phenotypes. Significant values $(q<0.05$, Spearman correlation) are annotated in blue. To determine the prediction power of b RFS, area under the receiver operating characteristic curves (AUROC) of our model (green line) was compared to stratification by MRD status at 4 months (light blue line) with the bootstrap method (number of iterations: 4000). Similarly, a combination of both models (red line) was developed and compared to stratification by MRD status at 4 months and original study protocol stratifications (dark blue line). Symbols for significance of the comparison: $* P<0.05, * * P<0.01$, $* * * P<0.001$. c The time-dependent receiver operating characteristic (ROC) curves (IPCW [inverse probability of censoring weighting] approach) and $C$-statistic values for RFS. Our prognostic model (green line) is compared to stratification by MRD status at 4 months postdiagnosis (light blue line). Their combined model (red line) is compared to stratification by MRD status at 4 months post-diagnosis and original study protocol stratifications (dark blue line). Significance is indicated at 2-, 4-, 6-, and 8-year time points with following symbols: ${ }^{\circ} P<0.10, * P<0.05, * * P<0.01, * * * P<0.001$

Our results showed that, when compared to healthy BM, in ALL, the proportion of antitumor-associated M1-like macrophages was decreased, and the proportion of protumorassociated M2-like macrophages and MDSCs was increased, consistent with previous studies [50]. Also the proportion of NK cells was lower, as has been previously described [51]. Further, antigen-presenting $\mathrm{mDC} 1 \mathrm{~s}$ and the proportion of CD4+ memory T cells were enriched in ALL BM advocating for possible augmented antigenpresentation capability.

$\mathrm{T}$ cells are perceived as the pivotal effector cell type in immuno-oncology and most likely also in B cell ALL owing to the success of treatments such as CD19-targeted CAR $T$ cell therapy and $\mathrm{T}$ cell engaging therapies [16-18, $52,53]$. Their level of infiltration into the tumor core and invasive margin might predict, at least in colorectal cancer, survival with higher accuracy than the classical tumornode-metastasis classification [40, 41]. Leukemia lacks an objective central tumor and invasive margin, thus making spatial immune stratification inapplicable.

Given the essential role linked to $\mathrm{T}$ cells, we designed the characterization panels to focus on $\mathrm{T}$ cells and their immunophenotype. Overall, the proportion of CD27+ $\mathrm{T}$ cells and $\mathrm{CD} 8+$ granzyme $\mathrm{B}+\mathrm{CD} 57+\mathrm{T}$ cells was decreased, and the expression of immune checkpoint molecules PD1 and CTLA4 on T cells was increased. On the other hand, the expression of LAG3 and TIM3 was decreased and the expression of OX40 on CD4+ T cells increased, but not on CD8 $+\mathrm{T}$ cells. The reason for contradictory expression patterns of immune checkpoint molecules remains unclear but might be explained with different regulatory signaling pathways. Immune checkpoint inhibitors have gained a strong foothold especially in the treatment of metastatic melanoma and non-small-cell lung cancer. Currently limited data are available on their 
efficacy in ALL; however, several studies regarding the use of anti-PD1 (NCT02819804, NCT02767934) and antiCTLA4 (NCT02879695, NCT01919619) antibodies in ALL are ongoing.

Interestingly, the high number of CD4+PD1+TIM3+ double-positive $\mathrm{T}$ cells, advanced age, and low platelet count at diagnosis differentiated a poor survival group in two separate cohorts. Our model outweighed stratification by MRD and the original study protocol risk classification in predicting long-term survival in our small Discovery cohort, but the combination of our model with simple MRD prediction strengthened them both. It is, however, fair to keep in mind, that there were relatively few NOPHOALL2008 patients, and almost all of them fell in the highrisk category, making objective assessment of these two study protocol risk stratifications in our study cohort inapplicable. While the model has to be validated in a larger cohort, the high-risk group seemed to be associated with higher BM blast proportion and PB leukocyte count, which are markers of high disease burden. High expression of CD4+PD1+TIM3 $+\mathrm{T}$ cells might predict poor survival in adult $\mathrm{B}$ cell ALL patients [54]. Interestingly, high CD4 $+\mathrm{PD} 1+\mathrm{TIM} 3+\mathrm{T}$ cell proportion was associated with cytolytic ( $\mathrm{T}$ cells and GrB expression), senescent (CD57 expression), and suppressive immune subsets (MDSCs). Despite remaining unexplained by our study, PD1+TIM3 $+\mathrm{CD} 4+\mathrm{T}$ cells might arise from prolonged immune response against blasts, e.g., immune exhaustion, or chronic inflammation related to BM expansion $[55,56]$. While these quantitative findings are merely descriptive by nature, decreased effector and increased immunoregulatory phenotype prevailing in ALL BM might reflect a switch from immune activation to immunosuppressive state. Further functional studies are warranted to address this question. In addition, as aging affects the immune system substantially [57], it would be interesting to investigate the immune microenvironment in pediatric ALL BM.

In conclusion, our results suggest that ALL BM has a unique immune cell composition that is also associated with clinical response to therapy. Additional research clarifying the impact of ALL immunobiology on disease progression and solving how to translate the immunophenotype features into treatment biomarkers remain imperative.

Acknowledgements This study was supported by the Doctoral Programme in Biomedicine (DPBM) and the Doctoral Programme in Clinical Research in the University of Helsinki and personal grants (to $\mathrm{OB}, \mathrm{SB}$ ) from Emil Aaltonen Foundation, research grants (to SM) from the Finnish Cancer Institute, Finnish Cancer Organizations, Sigrid Juselius Foundation, Signe and Ane Gyllenberg Foundation, Relander Foundation, Incyte Nordic Grant, and State funding for university-level health research in Finland. We thank Tiina Kasanen, a laboratory technician in the Hematology Research Unit Helsinki; Antonio Ribeiro, a laboratory technician in Professor Kallioniemi's laboratory, and the Department of Clinical Chemistry, Laboratory of
Hematology at the Helsinki University Hospital for technical support with FC. We are grateful to the members of the Hematology Research Unit Helsinki for discussions and technical help. We thank the Helsinki Biobank and the Digital and Molecular Pathology Unit supported by Helsinki University and Biocenter Finland. The samples and data used in the validation cohort of this project were provided by the Finnish Hematology Registry and Clinical Biobank (FHRB) with appropriate ethics approval (Dnro 202/06.01.00/2013). We thank all the patients for their generous participation. The FHRB Biobank is supported by the Finnish Association of Hematology, the Finnish Red Cross Blood Service, Institute for Molecular Medicine Finland, and the participating hospitals in Finland.

Author contributions Conception and design: $\mathrm{OB}, \mathrm{HH}, \mathrm{SB}, \mathrm{OK}, \mathrm{TP}$, SM. Collection and assembly of data: OB, HH, MS, PEK, KP. Data analysis and interpretation: OB, HH, RT, SB, TP, SM. Manuscript writing: all authors. Final approval of manuscript: all authors.

\section{Compliance with ethical standards}

Conflict of interest KP and SM have received honoraria and research funding from Pfizer, Novartis, and Bristol-Myers Squibb. S.B. is employed by Fimmic Oy. HH has received research funding from Incyte. The other authors declare that they have no conflict of interest.

Publisher's note: Springer Nature remains neutral with regard to jurisdictional claims in published maps and institutional affiliations.

Open Access This article is licensed under a Creative Commons Attribution 4.0 International License, which permits use, sharing, adaptation, distribution and reproduction in any medium or format, as long as you give appropriate credit to the original author(s) and the source, provide a link to the Creative Commons license, and indicate if changes were made. The images or other third party material in this article are included in the article's Creative Commons license, unless indicated otherwise in a credit line to the material. If material is not included in the article's Creative Commons license and your intended use is not permitted by statutory regulation or exceeds the permitted use, you will need to obtain permission directly from the copyright holder. To view a copy of this license, visit http://creativecommons. org/licenses/by/4.0/.

\section{References}

1. Inaba H, Greaves M, Mullighan CG. Acute lymphoblastic leukaemia. Lancet. 2013;381:1943-55.

2. Pui C-H, Evans WE. Treatment of acute lymphoblastic leukemia. N Engl J Med. 2006;354:166-78.

3. Toft N, Birgens H, Abrahamsson J, Griškevičius L, Hallböök H, Heyman M, et al. Results of NOPHO ALL2008 treatment for patients aged 1-45 years with acute lymphoblastic leukemia. Leukemia. 2017;124:796.

4. Seftel MD, Neuberg D, Zhang M-J, Wang H-L, Ballen KK, Bergeron $\mathrm{J}$, et al. Pediatric-inspired therapy compared to allografting for Philadelphia chromosome-negative adult ALL in first complete remission. Am J Hematol. 2016;91:322-9.

5. Huguet F, Leguay T, Raffoux E, Thomas X, Beldjord K, Delabesse E, et al. Pediatric-inspired therapy in adults with Philadelphia chromosome-negative acute lymphoblastic leukemia: the GRAALL-2003 study. J Clin Oncol. 2009;27:911-8.

6. Moorman AV, Harrison CJ, Buck GAN, Richards SM, SeckerWalker LM, Martineau M, et al. Karyotype is an independent prognostic factor in adult acute lymphoblastic leukemia (ALL): 
analysis of cytogenetic data from patients treated on the Medical Research Council (MRC) UKALLXII/Eastern Cooperative Oncology Group (ECOG) 2993 trial. Blood. 2007;109:3189-97.

7. Fielding AK, Rowe JM, Buck G, Foroni L, Gerrard G, Litzow MR, et al. UKALLXII/ECOG2993: addition of imatinib to a standard treatment regimen enhances long-term outcomes in Philadelphia positive acute lymphoblastic leukemia. Blood. 2014;123:843-50.

8. Daver N, Thomas D, Ravandi F, Cortes J, Garris R, Jabbour E, et al. Final report of a phase II study of imatinib mesylate with hyper-CVAD for the front-line treatment of adult patients with Philadelphia chromosome-positive acute lymphoblastic leukemia. Haematologica. 2015;100:653-61.

9. de Labarthe A, Rousselot P, Huguet-Rigal F, Delabesse E, Witz F, Maury S, et al. Imatinib combined with induction or consolidation chemotherapy in patients with de novo Philadelphia chromosomepositive acute lymphoblastic leukemia: results of the GRAAPH2003 study. Blood. 2007;109:1408-13.

10. Kreutzman A, Porkka K, Mustjoki S. Immunomodulatory effects of tyrosine kinase inhibitors. Int Trends Immun. 2013;1:22-33.

11. Riva G, Luppi M, Barozzi P, Quadrelli C, Basso S, Vallerini D, et al. Emergence of BCR-ABL-specific cytotoxic T cells in the bone marrow of patients with $\mathrm{Ph}+$ acute lymphoblastic leukemia during long-term imatinib mesylate treatment. Blood. 2010;115:1512-8.

12. Hekim C, Ilander M, Yan J, Michaud E, Smykla R, Vähä-Koskela $\mathrm{M}$, et al. Dasatinib changes immune cell profiles concomitant with reduced tumor growth in several murine solid tumor models. Cancer Immunol Res. 2017;5:157-69.

13. Balachandran VP, Cavnar MJ, Zeng S, Bamboat ZM, Ocuin LM, Obaid $\mathrm{H}$, et al. Imatinib potentiates antitumor $\mathrm{T}$ cell responses in gastrointestinal stromal tumor through the inhibition of Ido. Nat Med. 2011;17:1094-1100.

14. Mustjoki S, Auvinen K, Kreutzman A, Rousselot P, Hernesniemi $\mathrm{S}$, Melo $\mathrm{T}$, et al. Rapid mobilization of cytotoxic lymphocytes induced by dasatinib therapy. Leukemia. 2013;27:914-24.

15. Maury S, Chevret S, Thomas X, Heim D, Leguay T, Huguet F, et al. Rituximab in B-lineage adult acute lymphoblastic leukemia. N Engl J Med. 2016;375:1044-53.

16. Kantarjian H, Stein A, Gökbuget N, Fielding AK, Schuh AC, Ribera J-M, et al. Blinatumomab versus chemotherapy for advanced acute lymphoblastic leukemia. $\mathrm{N}$ Engl J Med. 2017;376:836-47.

17. Kantarjian H, Ravandi F, Short NJ, Huang X, Jain N, Sasaki K, et al. Inotuzumab ozogamicin in combination with low-intensity chemotherapy for older patients with Philadelphia chromosomenegative acute lymphoblastic leukaemia: a single-arm, phase 2 study. Lancet Oncol. 2018;19:240-8.

18. Park JH, Riviere I, Gonen M, Wang X, Sénéchal B, Curran KJ, et al. Long-term follow-up of CD19 CAR therapy in acute lymphoblastic leukemia. N Engl J Med. 2018;378:449-59.

19. Fridman WH, Pagès F, Sautès-Fridman $C$, Galon J. The immune contexture in human tumours: impact on clinical outcome. Nat Rev Cancer. 2012;12:298-306.

20. Andersen MH. The targeting of immunosuppressive mechanisms in hematological malignancies. Leukemia. 2014;28:1784-92.

21. Manlove LS, Berquam-Vrieze KE, Pauken KE, Williams RT, Jenkins MK, Farrar MA. Adaptive immunity to leukemia is inhibited by cross-reactive induced regulatory T cells. J Immunol. 2015;195:4028-37.

22. Blom S, Paavolainen L, Bychkov D, Turkki R, Mäki-Teeri P, Hemmes A, et al. Systems pathology by multiplexed immunohistochemistry and whole-slide digital image analysis. Sci Rep. 2017;7:15580.

23. Brück O, Blom S, Dufva O, Turkki R, Chheda H, Ribeiro A, et al. Immune cell contexture in the bone marrow tumor microenvironment impacts therapy response in CML. Leukemia. 2018;32:1643-56.

24. Ruifrok AC, Johnston DA. Quantification of histochemical staining by color deconvolution. Anal Quant Cytol Histol. 2001;23:291-9.

25. Reddy BS, Chatterji BN. An FFT-based technique for translation, rotation, and scale-invariant image registration. IEEE Trans Image Process. 1996;5:1266-71.

26. Carpenter AE, Jones TR, Lamprecht MR, Clarke C, Kang IH, Friman O, et al. CellProfiler: image analysis software for identifying and quantifying cell phenotypes. Genome Biol. 2006;7: R100.

27. Xing F, Yang L. Robust nucleus/cell detection and segmentation in digital pathology and microscopy images: a comprehensive review. IEEE Rev Biomed Eng. 2016;9:234-63.

28. Caicedo JC, Cooper S, Heigwer F, Warchal S, Qiu P, Molnar C, et al. Data-analysis strategies for image-based cell profiling. Nat Methods. 2017;14:849-63.

29. Benjamini Y, Hochberg Y. Controlling the false discovery rate: a practical and powerful approach to multiple testing. J R Stat Soc Ser B Methodol. 1995;57:289-300.

30. Tibshirani R. Regression shrinkage and selection via the lasso: a retrospective. J R Stat Soc: Ser B (Stat Methodol). 2011;73:27382.

31. Fine JP, Gray RJ. A proportional hazards model for the subdistribution of a competing risk. J Am Stat Assoc. 1999;94:496.

32. RStudio Team. RStudio: Integrated Development for R. Boston, MA: RStudio, Inc.; 2015. http://www.rstudio.com/.

33. Fridman WH, Zitvogel L, Sautès-Fridman C, Kroemer G. The immune contexture in cancer prognosis and treatment. Nat Rev Clin Oncol. 2017;14:717-34.

34. Galdiero MR, Garlanda C, Jaillon S, Marone G, Mantovani A. Tumor associated macrophages and neutrophils in tumor progression. J Cell Physiol. 2013;228:1404-12.

35. Gabrilovich DI, Ostrand-Rosenberg S, Bronte V. Coordinated regulation of myeloid cells by tumours. Nat Rev Immunol. 2012;12:253-68.

36. Nizzoli G, Krietsch J, Weick A, Steinfelder S, Facciotti F, Gruarin P, et al. Human CD1c+dendritic cells secrete high levels of IL-12 and potently prime cytotoxic T-cell responses. Blood. 2013;122:932-42.

37. Berry DA, Zhou S, Higley H, Mukundan L, Fu S, Reaman GH. et al. Association of minimal residual disease with clinical outcome in pediatric and adult acute lymphoblastic leukemia: a metaanalysis. JAMA Oncol. 2017;3:e170580.

38. Kononen J, Bubendorf L, Kallioniemi A, Bärlund M, Schraml P, Leighton S, et al. Tissue microarrays for high-throughput molecular profiling of tumor specimens. Nat Med. 1998;4:844-7.

39. Costantini A, Mancini S, Giuliodoro S, Butini L, Regnery CM, Silvestri G, et al. Effects of cryopreservation on lymphocyte immunophenotype and function. $\mathrm{J}$ Immunol Methods. 2003;278:145-55.

40. Galon J, Mlecnik B, Bindea G, Angell HK, Berger A, Lagorce C, et al. Towards the introduction of the 'Immunoscore' in the classification of malignant tumours. J Pathol. 2014;232:199-209.

41. Mlecnik B, Bindea G, Angell HK, Maby P, Angelova M, Tougeron $\mathrm{D}$, et al. Integrative analyses of colorectal cancer show immunoscore is a stronger predictor of patient survival than microsatellite instability. Immunity. 2016;44:698-711.

42. Denkert C, Loibl S, Noske A, Roller M, Müller BM, Komor M, et al. Tumor-associated lymphocytes as an independent predictor of response to neoadjuvant chemotherapy in breast cancer. J Clin Oncol. 2010;28:105-13.

43. García-Martínez E, Gil GL, Benito AC, González-Billalabeitia E, Conesa MAV, García TG, et al. Tumor-infiltrating immune cell profiles and their change after neoadjuvant chemotherapy predict 
response and prognosis of breast cancer. Breast Cancer Res. 2014;16:2303.

44. Ladoire S, Arnould L, Mignot G, Apetoh L, Rébé C, Martin F, et al. T-bet expression in intratumoral lymphoid structures after neoadjuvant trastuzumab plus docetaxel for HER2-overexpressing breast carcinoma predicts survival. $\mathrm{Br} \mathrm{J}$ Cancer. 2011; 105:366-71.

45. Blank CU, Haanen JB, Ribas A, Schumacher TN. Cancer immunology. The "cancer immunogram". Science. 2016;352:658-60.

46. Chen PL, Roh W, Reuben A, Cooper ZA, Spencer CN, Prieto PA, et al. Analysis of immune signatures in longitudinal tumor samples yields insight into biomarkers of response and mechanisms of resistance to immune checkpoint blockade. Cancer Discov. 2016;6:827-37.

47. Charoentong P, Finotello F, Angelova M, Mayer C, Efremova M, Rieder D, et al. Pan-cancer immunogenomic analyses reveal genotype-immunophenotype relationships and predictors of response to checkpoint blockade. Cell Rep. 2017;18:248-62.

48. Melero I, Berman DM, Aznar MA, Korman AJ, Pérez Gracia JL, Haanen J. Evolving synergistic combinations of targeted immunotherapies to combat cancer. Nat Rev Cancer. 2015;15:457-72.

49. Chen DS, Mellman I. Elements of cancer immunity and the cancer-immune set point. Nature. 2017;541:321-30.
50. Salem ML, El-Shanshory MR, Abdou SH, Attia MS, Sobhy SM, Zidan MF, et al. Chemotherapy alters the increased numbers of myeloid-derived suppressor and regulatory $\mathrm{T}$ cells in children with acute lymphoblastic leukemia. Immunopharmacol Immunotoxicol. 2018;40:158-67.

51. Rouce RH, Sekine T, Weber G, Chew C, Rezvani K, Bollard CM, et al. Natural killer cells in pediatric acute lymphoblastic leukemia patients at diagnosis demonstrate an inhibitory phenotype and reduced cytolytic capacity. Blood 2013;122:1397.

52. Maude SL, Frey N, Shaw PA, Aplenc R, Barrett DM, Bunin NJ, et al. Chimeric antigen receptor $\mathrm{T}$ cells for sustained remissions in leukemia. N Engl J Med. 2014;371:1507-17.

53. Joyce JA, Fearon DT. T cell exclusion, immune privilege, and the tumor microenvironment. Science. 2015;348:74-80.

54. Zhou Q, Munger ME, Veenstra RG, Weigel BJ, Hirashima M, Munn DH, et al. Coexpression of Tim-3 and PD-1 identifies a CD8+T-cell exhaustion phenotype in mice with disseminated acute myelogenous leukemia. Blood. 2011;117:4501-10.

55. de Visser KE, Eichten A, Coussens LM. Paradoxical roles of the immune system during cancer development. Nat Rev Cancer. 2006;6:24-37.

56. Mantovani A, Allavena P, Sica A, Balkwill F. Cancer-related inflammation. Nature. 2008;454:436-44.

57. Brodin P, Davis MM. Human immune system variation. Nat Rev Immunol. 2017;17:21-29. 